\title{
NEW CLUES ON THE MODEL OF YY HER AFTER TWO SEASONS
}

\author{
L. Hric, ${ }^{1}$ R. Gális, ${ }^{2}$ A. Dobrotka, ${ }^{3}$ V. Šimon, ${ }^{4}$ K. Petrík ${ }^{5}$ P. Niarchos,${ }^{6}$ Z. Velič ${ }^{7}$ K. Gazeas, ${ }^{6}$ L. S̆melcer ${ }^{8}$ \\ P. Hájek, ${ }^{9}$ P. Sobotka, ${ }^{10}$ K. Koss,${ }^{9}$ L. Brát, ${ }^{10}$ and F. Lomoz ${ }^{10}$
}

\section{During two observational seasons of interna- tional campaign of YY Her we secured pho- tometric data which covered the primary as well as the secondary minima and revealed unexpected outburst activity of this system.}

YY Her belongs to the classical symbiotic binaries with nova-like outbursts. Recently Mikolajewska et al. (2002) explained the light variability of YY Her by combining the ellipsoidal changes and sinusoidal variations of the nebular continuum and line emission. In 2001 (Hric et al. 2001) we discovered in the binary system YY Her the presence of the secondary minimum that was indicated, however, by only three photometric observations from one observatory. This uncertainty stimulated us to activate the international photometric campaign for detailed covering of the light curve during the period of the expected secondary minimum.

To this campaign were integrated the following observatories: Stará Lesná Observatory of the Astronomical Institute and Beluša Observatory in Slovakia. University of Athens and Kryonerion Observatory in Greece as well as Valašské Meziřričí Observatory, Vyskov Observatory, N. Copernicus Observatory Brno and Ondrejov Observatory of the Astronomical Institute in Czech Republic. We obtained in this campaign a total of $218,465,286$ and 291 observational data in $B, V, R$ and I filter respectively, that cover the interval of JD $2451823-2452877$.

There was a successful campaign conducted to also cover the primary minimum and it produced some interesting results. The periodic variations of the brightness are explained by the eclipses of the components in the symbiotic system. During the primary minimum about JD 2452440 we observed

\footnotetext{
${ }^{1}$ Astronomical Institute of the Slovak Academy of Sciences, 05960 Tatranská Lomnica, Slovakia (hric@ta3.sk).

${ }^{2}$ Faculty of Sciences, Eniversity of P. J. Šafárik, 04154 Košice, Slovakia (galis@kosice.upjs.sk).

${ }^{3}$ Faculty of Materials Science and Technology STI'. 91724 Trnava, Slovakia (dobrotka@mtf.stuba.sk).

${ }^{4}$ Astronomical Institute, 25165 Ondejov, Czech Republic.

${ }^{5}$ Faculty of Education, 918 .13 Trnava Iniversity, Slovakia.

${ }^{6}$ Faculty of Physics, University of Athens, Greece.

${ }^{7}$ Observatory, 01861 Beluša, Slovakia.

${ }^{8}$ Observatory, 75701 Valašské Meziřící. Czech Republic

${ }^{9}$ Observatory, 68201 Vyškov, Czech Republic.

${ }^{10}$ MEDUZA Group, 61601 Brno, Czech Republic.
}

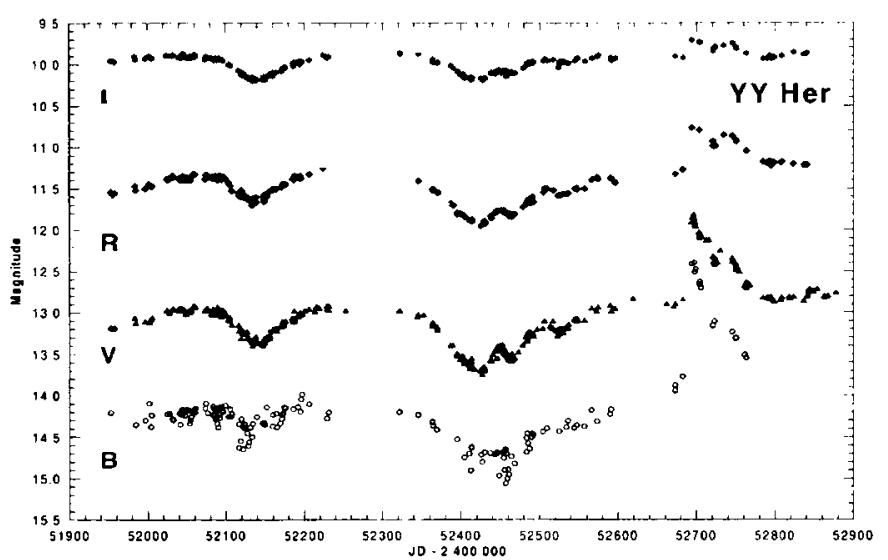

Fig. 1. BVRI photometry of YY Her secured during international campaign from 2001 to 2003.

the flares that were later followed by the energetic outburst in about JD 2452700.

At the first glance at the light curve it is evident that the amplitude of the outburst declines towards longer wavelengths while for the particular colour the following amplitudes in maximum were detected: $1.56 \mathrm{mag}$ in $\mathrm{B}, 1.04 \mathrm{in} \mathrm{V,} 0.54$ in $\mathrm{R}$ and 0.20 in I filter respectively. The monotonic decline of brightness from maximum was interrupted by an apparent dip. That coincides with the time of the secondary minimum.

In this paper we outlined the idea that the photometric behaviour of YY Her is possible to describe consistently by an eclipsing model. This explanation requires the presence of an optically thick envelope around the white dwarf with a temperature significantly lower than the temperature of the hot component. The existence of such an envelope is in agreement with assumptions about steady state burning of matter accreted on the white dwarf by a red giant wind. The occasionally observed outbursts are caused by transfer of blob of matter through $\mathrm{L}_{1}$, by collision in the ring (the first weaker outburst) and by following impact on the white dwarf (the second stronger outburst).

\section{REFERENCES}

Hric, L., Petrík, K., Niarchos, P., Velič, Z., Gális, R. 2001, IBVS No. 5046

Mikolajewska, J., Kolotilov, E.A., Shugarov, S. Yu, Yudin, B.F. 2002, AA 392, 197 